\title{
Experimental Study on the Treatment of 1, 4 butanediol Mixed Wastewater by Ferro-carbon Micro-electrolysis
}

\author{
Jie Lei ${ }^{1, *}$, Xiaodong Zhang ${ }^{2}$, zhenglin Zhou ${ }^{3}$, Shaohui Fan ${ }^{4}$, Bo Jiang ${ }^{5}$, Xianlan Tian ${ }^{6}$ \\ Xi 'an, 727400 , China
}

\begin{abstract}
The mixed wastewater of 1, 4 butanediol was tested with iron filings and carbon powder as catalyst by aeration to provide oxygen. The effects of carbon powder, $\mathrm{pH}$ value and reaction time on wastewater treatment were studied. The optimal experimental condition was that the mesh number of activated carbons was 20 , the $\mathrm{pH}$ value was 5 , the reaction time was 30min, and the Chemical Oxygen Demand (COD) removal efficiency reached $36.2 \%$. At the same time, The response surface method was used to analyze and optimize the experimental results, and the relation formula of each influencing factor on removal efficiency was established, and the order of influence degree of each factor on removal efficiency $(\mathrm{pH}>$ activated carbon mesh number $>$ reaction time) was obtained, in which $\mathrm{pH}$ had the greatest influence on the treatment rate of ferro-carbon micro-electrolysis treatment of 1, 4-butanediol wastewater.
\end{abstract}

\section{Introduction}

1, 4 butanediol is an important organic chemical raw material, which is widely used in pharmaceutical chemical textile paper cars and daily chemical industry ${ }^{[5]}$. At present, the commonly used production technology is alkyl aldehyde method, and the products are 1,4butanediol (THF), 1,4butyne glycol (BYD), polytetrahydrofuran (PTMEG) etc. THF and PTMEG is a kind of toxic organic compounds, from structural analysis belongs to refractory material, is great harm to human health ${ }^{[1]}{ }^{[2]}$.

Ferro-carbon micro-electrolysis used the metal corrosion principle method to conduct electrolytic treatment of the waste water, by using the self-generated $1.2 \mathrm{~V}$ potential difference of the micro-electrolytic material filled in the waste water without power, and achieve the purpose of degrading organic pollutants. Under acidic conditions, it is conducive to the micro-electrolysis reaction, which can speed up the reaction rate. The oxidation reduction reaction of dissolved oxygen and $\mathrm{Fe}^{2+}$ in wastewater will destroy the molecular structure of some organic substances. The $\mathrm{Fe}^{3+}$ will flocculate the organic substances in waste water and further remove the pollutants ${ }^{[3]}$. Activated carbon surface contains a large number of acidic or alkaline groups, which have adsorption capacity and

* Corresponding author: epleijie@aliyun.com 
catalytic effect. When there is $\mathrm{O}_{2}$ or hydrogen peroxide $\left(\mathrm{H}_{2} \mathrm{O}_{2}\right)$ in wastewater, the pollutants in wastewater are catalyzed and oxidized ${ }^{[4]}$.

In this study, 1, 4 butanediol mixed wastewater was taken as the research object, air was taken as the oxidant, and the effects factors such as $\mathrm{pH}$, reaction time and activated carbon mesh number were studied. The experimental results indicated that the activated carbon mesh number was $20, \mathrm{pH}$ value was 5 , reaction time was $30 \mathrm{~min}$, and the COD removal efficiency reached $36.2 \%$, which provided the fundamental researches for the Ferro-carbon micro-electrolytic treatment technology of 1, 4-butanediol mixed wastewater. Response Surface Methodology (RSM) was used to analyze and optimize the experimental results, and a quadratic polynomial mathematical model was established for the relationship between COD removal efficiency and various factors, and effect of the different factors on COD removal efficiency was analyzed.

\section{Materials and methods}

\subsection{Materials}

The wastewater comes from BDO and PTMEG production workshops of a chemical enterprise in China. The wastewater quality was as follows: COD $6000 \sim 12000 \mathrm{mg} \mathrm{L}^{-1}$, biochemical oxygen demand $\left(\mathrm{BOD}_{5}\right) \quad 596 \sim 1800 \mathrm{mg} \mathrm{L}^{-1}, \mathrm{~B} / \mathrm{C} 0.083 \sim 0.11, \mathrm{pH} \mathrm{6 \sim 9}$, salt concentration $0.06 \mathrm{wt} \%$. The main effluent discharge and pollutant concentration are shown in Table 1.

Table 1. Sewage discharge and pollution characteristics of a chemical enterprise in northwest china.

\begin{tabular}{ccccccc}
\hline No & Parameter & $\begin{array}{c}\text { Flow } \\
/ \mathrm{m}^{3} \mathrm{~h}^{-1}\end{array}$ & $\begin{array}{c}\text { Concentration } \\
/ \mathrm{mg} \mathrm{L}^{-1}\end{array}$ & Toxicity & Biodegradation & Pretreatment \\
\hline 1 & BDO & 20 & 1800 & $\mathrm{~N}$ & Easy & $\mathrm{N}$ \\
2 & BYD & 15 & 200 & $\mathrm{~N}$ & Difficult & $\mathrm{Y}$ \\
3 & HCHO & 10 & 3600 & $\mathrm{Y}$ & Bacteriostatic & $\mathrm{Y}$ \\
4 & PT/THF & 8 & 3700 & $\mathrm{Y}$ & Bacteriostatic & $\mathrm{Y}$ \\
\hline
\end{tabular}

\subsection{Test instrument}

The test instruments mainly include a small Ferro-carbon reactor and $\mathrm{pH}$ meter and COD meter and etc.

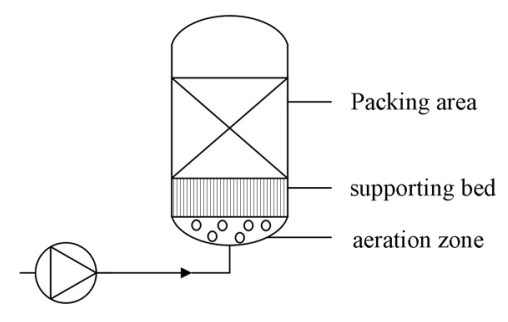

Air blower

Fig. 1. Structure of the Ferro-carbon reactor 


\section{HEET 2018}

\subsection{Methods}

(1) Rinse the activated carbon with clean water before use, soak it in the waste water, and dry it.

(2) Put the activated carbon and iron shavings in a self-made aeration device, which is full of waste water, then in the reaction.

(3) Adjust the $\mathrm{pH}$ of the reaction wastewater to $\mathrm{pH}$ near neutrally, and test the COD of the supernatant after filtration.

\section{Results and Discussion}

\subsection{Results}

\subsubsection{Effect of activated carbon mesh number on COD removal efficiency}

When the $\mathrm{Fe}-\mathrm{C}$ mass ratio was $1: 1$, the $\mathrm{pH}$ was 4 and the reaction time was 50 min, changed the mesh number of activated carbons, the removal efficiency of COD in wastewater after the reaction was shown in Table 2.

Table 2. Influence of activated carbon mesh number on COD removal efficiency

\begin{tabular}{ccccc}
\hline Activated carbon mesh & 8 & 15 & 20 & 30 \\
\hline Removal efficiency $/ \%$ & 20.8 & 24.4 & 34.8 & 23.9 \\
\hline
\end{tabular}

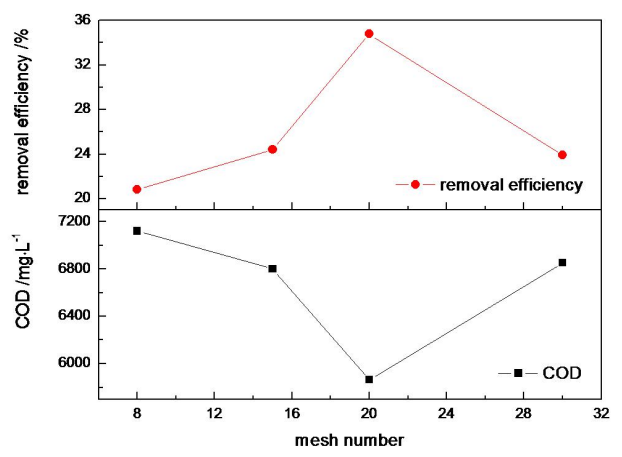

Fig. 2. Influence of activated carbon number on COD removal efficiency

\subsubsection{Effect of $\mathrm{pH}$ on COD removal efficiency}

As shown in Table 3, when the Fe-C mass ratio was 1:1, the $\mathrm{pH}$ was 4 and the reaction time was $50 \mathrm{~min}$. The removal efficiency of COD in waste water was changed by changing the $\mathrm{pH}$.

Table 3. Effect of $\mathrm{pH}$ on COD removal efficiency

\begin{tabular}{ccccccc}
\hline $\mathrm{pH}$ & 3 & 4 & 5 & 6 & 7 & 8 \\
\hline Removal efficiency $/ \%$ & 22.4 & 28.8 & 36.2 & 24.5 & 21.5 & 20.8 \\
\hline
\end{tabular}




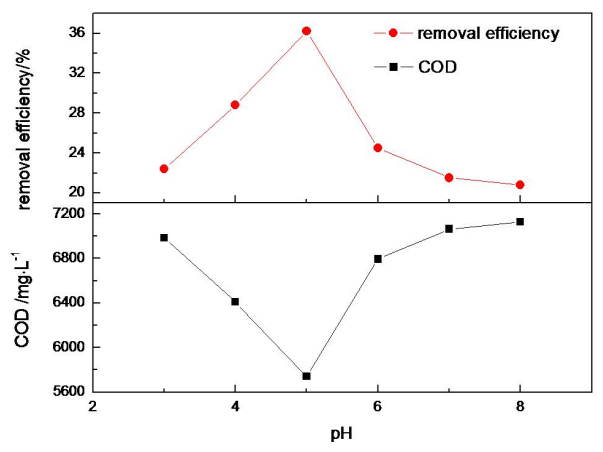

Fig. 3. Influence of $\mathrm{pH}$ on $\mathrm{COD}$ removal efficiency

As shown in Fig. 3, with the increase of $\mathrm{pH}$, COD removal first increased and then decreased. When the $\mathrm{pH}$ was 5 , the removal efficiency reached up to $36.2 \%$. When the $\mathrm{pH}$ was low, the treatment efficiency was generally better than the alkaline conditions. However, when $\mathrm{pH}$ was too low, iron dissolved a large amount of $\mathrm{Fe}^{3+}$ and $\mathrm{Fe}^{3+}$ causes flocculation and precipitation of organics, which is easy to cause packing blockage, which was not conducive to the formation of the original battery and the removal of COD. On the other hand, when $\mathrm{pH}$ was alkaline, $\mathrm{H}^{+}$concentration was low, which was also not conducive to the formation of the original battery and reduced the COD removal efficiency on the effect of Ferro-carbon micro-electrolysis.

\subsubsection{Effect of reaction time on COD removal efficiency}

When the Fe-C mass ratio was $1: 1$ and the $\mathrm{pH}$ value was 5 and the activated carbon number was 20 , changes the reaction time, the removal efficiency of COD in the wastewater after the reaction was shown in Table 4.

Table 4. Effect of reaction time on COD removal efficiency

\begin{tabular}{cccccc}
\hline Reaction time $/ \mathrm{min}$ & 10 & 20 & 30 & 40 & 50 \\
\hline Removal efficiency $/ \%$ & 25 & 26 & 33.5 & 34.6 & 35.2 \\
\hline
\end{tabular}

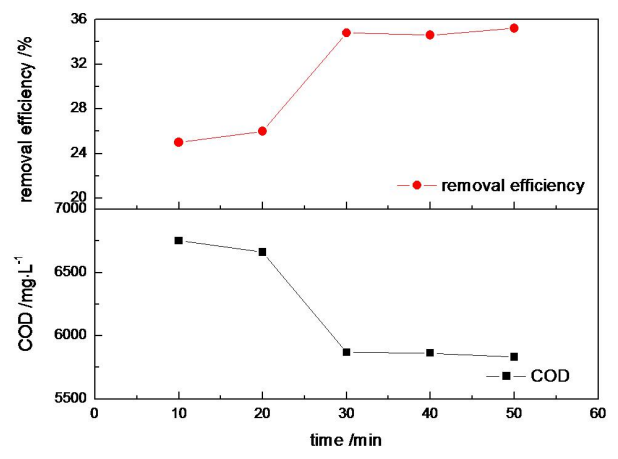

Fig. 4. Reaction time of $\mathrm{pH}$ on COD removal efficiency

Fig. 4 shows that, with the extension of reaction time, the removal efficiency of COD gradually increases. When the reaction time was $30 \mathrm{~min}$, the removal efficiency was $33.5 \%$. 
When the reaction time exceeded 30min, the removal efficiency of COD increased slowly with the increase of reaction time, and remains basically unchanged. The possible mechanism is that the oxidative effect of Ferro-carbon microcells is close to the maximum treatment capacity of pollutant degradation. Meanwhile, the adsorption and catalytic oxidation of activated carbon to COD achieves the dynamic balance under certain pollutant concentration and aeration conditions.

\subsection{Discussion}

Response Surface Methodology (RSM) is a mathematical statistical method for optimization of multi-factor system, which has been widely used in optimization of various waste water treatment processes, is a reliable and simple statistical tool ${ }^{[7][8]}$.

In this study, RSM was used to analyze and optimize the main influencing factors, which includes the mesh number of activated carbons, $\mathrm{pH}$ and the reaction time, in the process of Ferro-carbon micro-electrolysis treatment of 1, 4-butanediol mixed wastewater.

A quadratic polynomial was established for the relationship between the response R1 (COD removal efficiency) and each parameter (reaction time $\mathrm{A}, \mathrm{pH}$ is $\mathrm{B}$, and the mesh number of activated carbon is $\mathrm{C}$ ), which is coded as follows:

$$
R 1=30.6+0.077 A-1.91 B+0.19 C+0.04 A B+0.02 A C+0.08 B C
$$

The A, B and C are encoding values of the response parameters, the factors before the encoding values represent the influence direction and influence the degree of the parameters ${ }^{[7]}$. According to the formula:

$$
R 1=30.6+0.077 A-1.91 B+0.19 C+0.04 A B+0.02 A C+0.08 B C
$$

The study of Ferro-carbon micro-electrolysis conducts that the number of time and activated carbon has a positive effect on the response $\mathrm{R} 1$, while the $\mathrm{pH}$ has a negative effect on the response volume $\mathrm{R} 1$. The order of influence degree was: $\mathrm{pH}>$ the mesh number of activated carbons $>$ reaction time, and $\mathrm{pH}$ had the greatest influence on the treatment efficiency of 1, 4 butanediol wastewater by Ferro-carbon micro-electrolysis.

Table 5. Experimental results of 1,4butanediol wastewater

\begin{tabular}{ccccc}
\hline NO & A time/ min & B pH & C mesh & Removal efficiency / \% \\
\hline 1 & 50 & 7 & 30 & 16 \\
2 & 50 & 3 & 8 & 28.9 \\
3 & 50 & 3 & 30 & 34.6 \\
4 & 10 & 7 & 30 & 26 \\
5 & 10 & 7 & 8 & 21 \\
6 & 10 & 3 & 30 & 28 \\
7 & 50 & 7 & 8 & 24 \\
8 & 10 & 3 & 8 & 26 \\
\hline
\end{tabular}




\subsubsection{Fitting optimization of $\mathrm{pH}$ with reaction time}

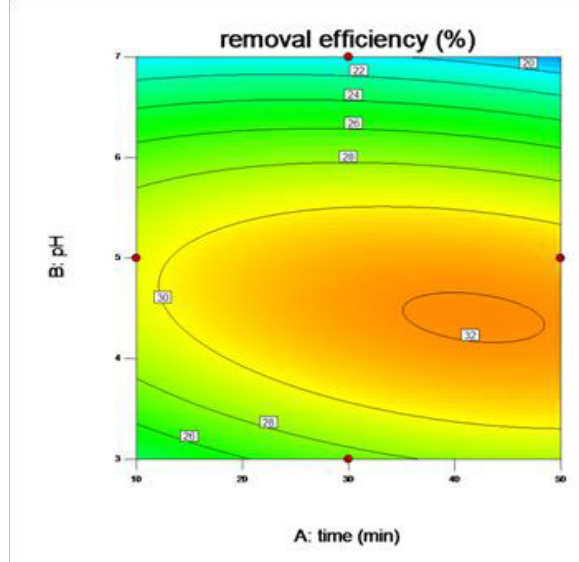

(a)

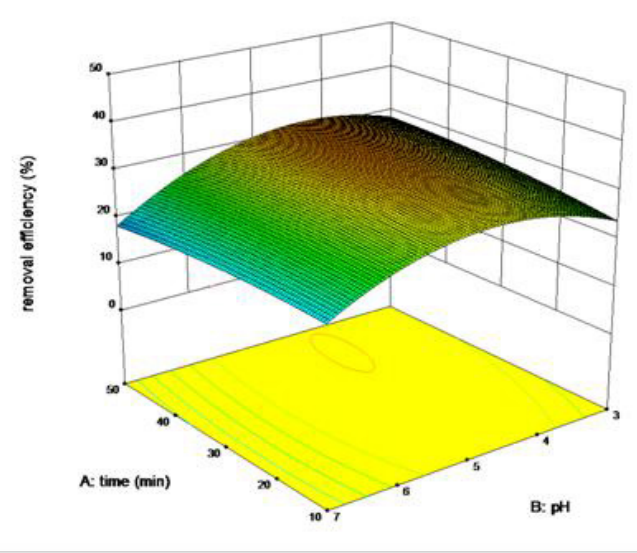

(b)

Fig. 5. Effect of reaction time and $\mathrm{pH}$ on COD removal efficiency (a) contour map (b) response surface map

Fig. 5 shows that under the condition of the activated carbon mesh number of 20 , the reaction time was greater than $30 \mathrm{~min}$, the reaction time affected the COD removal efficiency gently and the $\mathrm{pH}$ was the main factor influencing the COD removal efficiency. With the increase of $\mathrm{pH}$, COD removal efficiency first increased and then decreased, and the COD removal efficiency reached the maximum when $\mathrm{pH}$ was 5.

\subsubsection{Fitting optimization of activated carbon mesh number with the reaction time and $\mathrm{pH}$}

As shown in Fig.6 and Fig.7, through optimization analysis of various parameters, the reaction condition after optimization was as follows: the mesh number of activated carbons was 22 , the $\mathrm{pH}$ was 5 and the reaction time was about $28 \mathrm{~min}$.

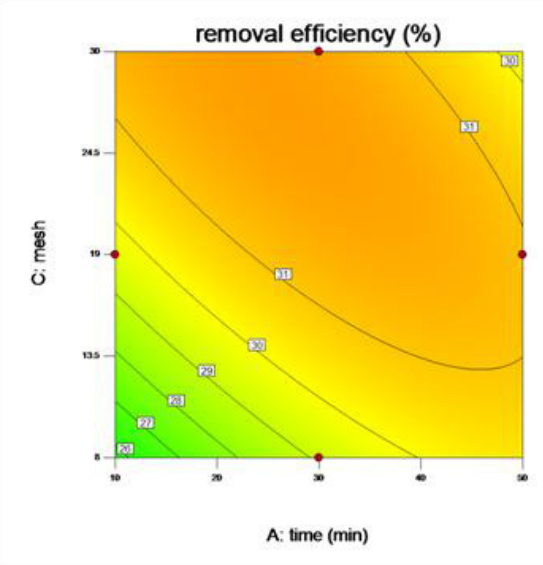

(a)

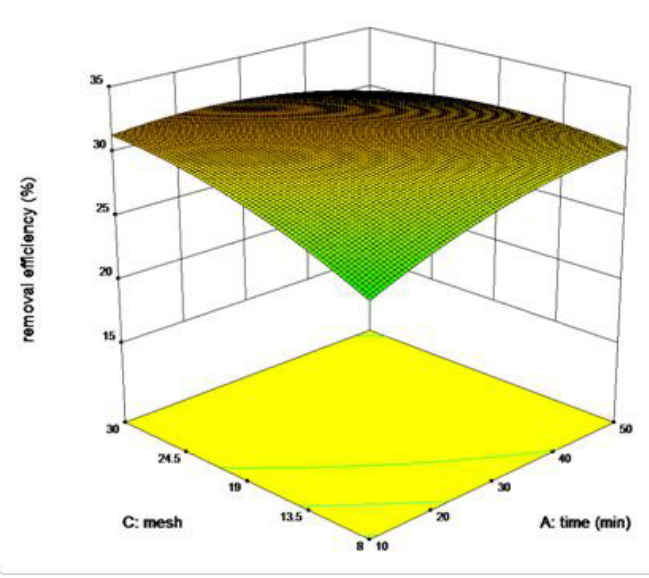

(b)

Fig. 6 Effect of reaction time and activated carbon mesh number on COD removal efficiency (a) contour map (b) response surface map 


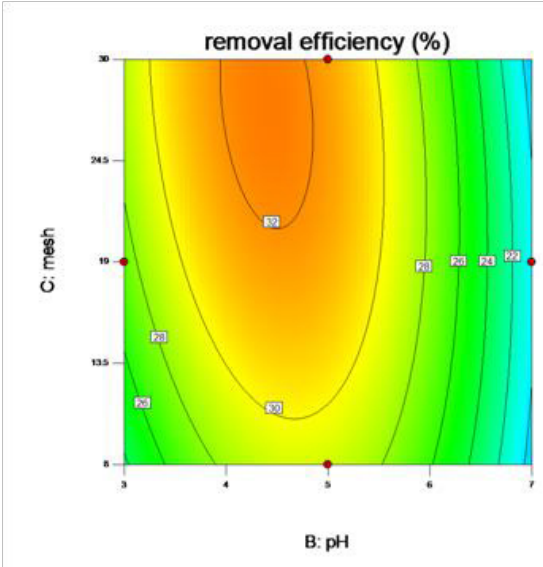

(a)

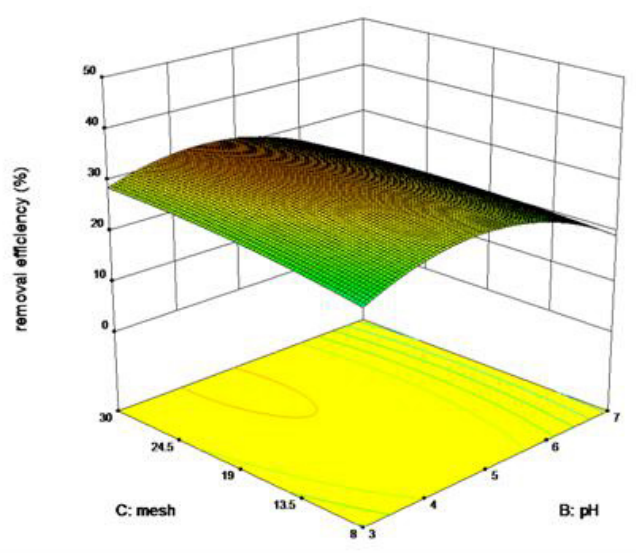

(b)

Fig. 7 Effect of $\mathrm{pH}$ and activated carbon mesh number on COD removal efficiency (a) contour map (b) response surface map

\section{Conclusions}

(1) The application of Ferro-carbon micro-electrolysis in the pretreatment of 1, 4butanediol wastewater, can reduce the pollution load of subsequent systems and improve the biochemical property of wastewater.

(2) When the activated carbon mesh number was $20, \mathrm{pH}$ value was 5 and reaction time was $30 \mathrm{~min}$, the removal efficiency of COD was $36.2 \%$.

(3) RSM method was used to optimize the experimental results. The optimal working condition: activated carbon mesh number was 22 , and $\mathrm{pH}$ value was 5 and reaction time was $28 \mathrm{~min}$.

Through the analysis of experimental results by RSM, the relationship between each influencing factor and COD removal efficiency is conducted, as follows:

$$
R 1=30.6+0.077 A-1.91 B+0.19 C+0.04 A B+0.02 A C+0.08 B C
$$

The reaction time and the mesh number of activated carbons have a positive effect on the COD removal efficiency, while the $\mathrm{pH}$ has a negative effect on the COD removal efficiency. The order of influence degree is: $\mathrm{pH}>$ the mesh number of activated carbons $>$ reaction time, and $\mathrm{pH}$ has the greatest influence on the treatment rate of 1,4 butanediol wastewater by Ferro-carbon micro-electrolysis.

\section{References}

1. H.X. Guo. Xi 'an University of Architecture and Technology, China (2004).

2. Z.H. Lu. College of Sciences Zhejiang University Hangzhou, China, May, (2008).

3. Y. Zuo, J. Liu, German et al. Environmental Science \& Technology, China, S2, 261262 (2010).

4. J.S. Wang, H. Mo. Journal of Lanzhou Railway University, China, 19:77-80, (2000).

5. Y. Wu, S.Y. Zhu, B. Cao, et al. Industrial Water Treatment, China, 35:41-43(2015). 
6. H. Zhang. Guangxi University, China (2013).

7. J. Zhang, S.Z. Wang, Y. Guo, et al. Xi 'an Jiao tong University, China (2010).

8. I. Arslanalaton, A. Akin, T. Olmezhanci. J CHEM TECHNOL BIOT, 85, 493501(2010). 